\title{
A VONTADE COMO FUNDAMENTO DA POLÍTICA EM AGOSTINHO *
}

The will while foundation of politics in Augustine

Luiz Marcos da Silva Filho **

Resumo: No livro XIX d'A cidade de Deus, Agostinho refuta a definição ciceroniana de populus, fundamentada na justiça, na natureza e na razão, e reformula-a segundo uma concepção de vontade ou amor. Tal empreendimento revela concepções distintas de justiça e natureza dos dois autores. Assim, o fundamento da política agostiniana não é nem a natureza, nem a razão, pois, notadamente contra Cícero, Agostinho empreende uma desnaturalização da política. Nosso propósito será investigar os traços do voluntarismo político agostiniano.

Palavras-chave: Política. Moral. Justiça. História. Vontade.

Abstract: In The city of God, book XIX, Augustine rejects the Ciceronian definition of populus, founded on justice, nature and reason, redefining it according to a conception of will or love. Such an endeavor reveals different conceptions of justice and nature. The Augustinian foundation of politics is neither nature nor reason, for, contrary to Cicero, Augustine argues for a denaturalization of politics. Our purpose here is to investigate the features of Augustinian political voluntarism.

Keys-words: Politics. Morals. Justice. History. Will.

* Este artigo é uma síntese da seção De definitionibus rei publicae et populi, do cap. III de nossa dissertação de mestrado e do cap. IV e "Considerações finais" de nossa tese de doutorado. Cf. SILVA FILHO, L. M. A definição de populus n'A cidade de Deus de Agostinho: uma controvérsia com Da república de Cícero. Dissertação de Mestrado em Filosofia, São Paulo, USP, 2008. SILVA FILHO, L. M. Desnaturalização da política n'A cidade de Deus, de Agostinho. Tese de Doutorado em Filosofia, São Paulo, USP, 2012.

** Pós-doutorando em Filosofia na Universidade Federal de São Carlos - UFSCar. Foi professor adjunto II de História da Filosofia Medieval, da Universidade Federal de Lavras - UFLA. Artigo recebido em 16/07/2017 e aprovado para publicação em 06/09/2017. 


\section{Introdução: o problema da politica em Agostinho}

A reflexão agostiniana sobre a política enfrenta a dificuldade de não poder recorrer a uma conceitualização comprometida com a identidade. Afinal, a condição histórica em que as cidades celeste e terrena existem é marcada pela irredutibilidade da contradição e do conflito. É verdade que a cidade celeste existe na história de forma não exclusiva, uma vez que existe também na eternidade, como logo as primeiras linhas do prólogo d'A cidade de Deus já anuncia ${ }^{1}$. Mas precisamente porque a cidade celeste existe também no tempo em regime de peregrinação, o desafio consiste em compreender o motivo pelo qual tanto ela, moralmente orientada, quanto a terrena, moralmente desorientada, guardam estatuto político na realidade histórica, porquanto ambas são ciuitates. Não à toa, a definição ciceroniana de "povo" 2 é imprecisa para Agostinho, pois ela interdita não apenas que os romanos constituam "povo" e "república", mas que todo e qualquer conjunto de inumeráveis homens estabeleça comunidade política na realidade histórica. Em Cícero, com efeito, uma multitudo precisa cumprir exigência naturalista e intelectualista para adquirir forma de populus, expressa notadamente pela condição iuris consensus ${ }^{3}$. Mas se o cumprimento de iuris consensus reclama estrita observância do direito, da justiça, da natureza e da razão, para Agostinho somente uma sociedade de santos seria capaz de realizá-lo, porque somente homens ou anjos com a natureza íntegra cumprem a virtude da justiça sem a resistência de vícios. Assim, se somente a cidade celeste em seu modo de existência na eternidade cumpre as condições ciceronianas para uma multitudo adquirir estatuto de populus, a consequência é a impossibilidade da política na história.

\footnotetext{
1 "A gloriosíssima cidade de Deus, tanto no curso dos tempos, enquanto peregrina entre os ímpios vivendo da fé, como na estabilidade da morada eterna, que agora espera com paciência, 'até que a justiça se converta em juízo', e que depois será alcançada pela excelência na vitória final e paz perfeita, é a cidade que eu, na feitura desta obra, dívida de promessa que te fiz, caríssimo filho Marcelino, encarreguei-me de defender contra aqueles que preferem seus deuses ao Fundador dela: grande e árdua tarefa, mas 'Deus é nosso auxílio'". "Gloriosissimam civitatem dei sive in hoc temporum cursu, cum inter impios peregrinatur ex fide vivens, sive in illa stabilitate sedis aeternae, quam nunc exspectat per patientiam, quoadusque iustitia convertatur in iudicium, deinceps adeptura per excellentiam victoria ultima et pace perfecta, hoc opere instituto et mea ad te promissione debito defendere adversus eos, qui conditori eius deos suos praeferunt, fili carissime Marcelline, suscepi, magnum opus et arduum, sed Deus adiutor noster est.". (AUGUSTINUS, De civitate Dei, 1955a, praefatio). Grifo nosso. Nossa tradução.

2 "[...] povo é não toda união de homens de qualquer modo congregados, mas a união de inumeráveis homens associados por consentimento jurídico e utilidade comum". "[...] populus [autem] non omnis hominum coetus quoquo modo congregatus, coetum multitudinis iuris consensu et utilitatis communione sociatum". (CICERO, De re publica, 1964, I, xxv, 39). Nossa tradução. ${ }^{3}$ Sobre o significado das condições da definição de populus em Cícero e sua ambiência estoica, cf.: SILVA FILHO, L. M., A conjunção et na definição ciceroniana de populus, in: Cadernos de Filosofia Alemã, 2013, pp. 85-96.
} 
Em outras palavras, a partir da leitura agostiniana da definição ciceroniana de populus, história e política são inconciliáveis e esta apenas poderia existir na transcendência. A tarefa agostiniana, dessa forma, é discernir princípio e fundamento da política que possa ser imanente à história. $\mathrm{O}$ conceito em questão será o de "vontade" ou "amor", precisamente porque nele há dinâmica que o torna em si mesmo neutro, adquirindo positividade ou negatividade conforme o lugar para onde for direcionado. Não sem razão, Agostinho encerra o livro XIV d'A cidade de Deus com explicitação do princípio e o fundamento voluntarista da história e da política.

Dois amores fundaram, pois, duas cidades: o amor de si, levado ao desprezo de Deus, a terrena; o amor a Deus, levado ao desprezo de si, a celeste. A primeira se glorifica em si mesma, a segunda no Senhor, porque aquela busca a glória dos homens e esta tem por máxima glória Deus como testemunha de sua consciência. Aquela ensoberbece-se em sua glória e esta diz a seu Deus: "Sois minha glória e quem me exalta a cabeça". Naquela, a libido de dominação domina seus príncipes e as nações subjugadas; nesta, servem em recíproca caridade, os governantes, aconselhando, e os súditos, obedecendo. ${ }^{4}$

O amor, assim, concede que a política seja concebida a partir de uma ambivalência, possibilitada pelo expediente de não a fundamentar nem na natureza, nem na razão. Como o amor apenas adquire positividade ou negatividade conforme o seu fim, tanto uma república moralmente orientada, como a celeste, quanto uma moralmente desorientada, como a terrena, são "repúblicas" com respectivos "povos". Isso significa que Agostinho não estabelecerá critério moral para conferir estatuto político para um conjunto de homens associados ${ }^{5}$. Eis por que a ruptura com a política ciceroniana exige redefinição de populus com ausência de critério moral e dos conceitos de justiça, natureza e razão como condição para uma multitudo alcançar forma política. Tratemos, então, de investigar a definição agostiniana de "povo" disposta n'A cidade de Deus, XIX, xxiv, em refutação à ciceroniana, mas não sem analisar os passos argumentativos do texto anteriores à emergência da nova definição.

\footnotetext{
4 "Fecerunt itaque civitates duas amores duo, terrenam scilicet amor sui usque ad contemptum Dei, caelestem vero amor Dei usque ad contemptum sui. Denique illa in se ipsa, haec in Domino gloriatur. Illa enim quaerit ab hominibus gloriam; huic autem Deus conscientiae testis maxima est gloria. Illa in gloria sua exaltat caput suum; haec dicit Deo suo: Gloria mea et exaltans caput meum (Sl 3, 4). Illi in principibus eius vel in eis quas subiugat nationibus dominandi libido dominatur; in hac serviunt invicem in caritate et praepositi consulendo et subditi obtemperando." (AUGUSTINUS, De civitate Dei, 1955b, XIV, xxviii). Na ausência de menção, as traduções d'A cidade de Deus são de Oscar Paes Leme com modificação nossa.

${ }^{5}$ Sobre a relação entre política e moral em Agostinho a partir da definição de populus, cf. ADAMS, J. D., "Augustine's Definitions of Populus and the Value of Civil Society", in: DONNELLY, D. F. (ed.) The City of God, 1995, pp. 171-182; O'DONOVAN, O., "Augustine's City of God XIX and Western Political Thought"., in: IDEM, 1995, pp. 135-149.
} 


\section{Crítica à definição ciceroniana de "povo" (A cidade de \\ Deus, XIX, xxi)}

N'A cidade de Deus, XIX, xxi, Agostinho reconstitui parte dos livros I e III do diálogo Da república e, assim, dispõe na própria obra as definições de res publica e de populus de Cícero. A definição ciceroniana de república é etimológica: "coisa do povo" ${ }^{\prime 6}$. Definida a república, Cícero precisa definir o que seja "povo", e assim procede ao dizer que é "a união de muitos homens por consentimento jurídico e utilidade comum" ${ }^{\prime 7}$. Para Agostinho, por consequência, "a República Romana nunca existiu, porque, segundo essas definições, nunca foi coisa do povo" ${ }^{\prime \prime}$. Em seguida, Agostinho diz que, para Cícero, consentimento jurídico precisa ser compreendido a par de justiça. "A república não pode ser governada sem justiça, pois onde não há verdadeira justiça, não pode haver verdadeiro direito." "' Se onde não há "justiça" não pode haver "consentimento jurídico", tampouco pode haver "povo". A conclusão agostiniana é óbvia: "se não existe povo, não há república" ${ }^{10}$. Esse, para Agostinho, sempre foi o caso da "República Romana" porque segundo a definição de justiça, que é a virtude que "dá a cada um o que lhe é devido" ${ }^{11}$, os cidadãos romanos nunca tiveram essa virtude.

A justiça é a virtude que dá a cada um o que lhe é devido. Que justiça é a do homem que do verdadeiro Deus afasta o próprio homem e o submete aos imundos demônios? Isso é, porventura, dar a cada um o que lhe é devido? Ou será que quem tira a propriedade a quem a comprou e a dá a quem não tem nada de direito a ela é injusto, e é justo quem se furta ao Deus dominador que o criou e serve os espíritos malignos? ${ }^{12}$.

Para Agostinho, o próprio Cícero admite que o homem não cumpre a justiça ao dizer em seu diálogo que quando "Deus manda no homem, a alma manda no corpo, a razão na libido e em outros vícios da alma" ${ }^{13}$. Assim, se Deus não impera sobre o homem, nele a justiça não pode existir, já que quando ele "não serve a Deus, de nenhum modo a alma pode

\footnotetext{
6 "rem populi". (AUGUSTINUS, 1955b, XIX, xxi, 1).

7 "[...] coetum multitudinis iuris consensu et utilitatis communione sociatum". (AUGUSTINUS, 1955b, XIX, xxi, 1); CICERO, 1964, I, xxv, 39.

8 "secundum definitiones, [...] numquam fuit Romana res publica, quia numquam fuit res populi". (AUGUSTINUS, 1955b XIX, xxi, 1). Cf. CICERO, 1964, I, xxv, 39.

9 "[...] geri sine iustitia non posse rempublicam; ubi ergo iustitia vera non est, nec ius potest esse." (AUGUSTINUS, 1955b, XIX, xxi, 1).

10 "[...] et si non populus, nec res populi". (AUGUSTINUS, 1955b, XIX, xxi, 1).

11 "[...] quae sua cuique distribuit". (AUGUSTINUS, 1955b, XIX, xxi, 01).

12 "Iustitia porro ea virtus est, quae sua cuique distribuit. Quae igitur iustitia est hominis, quae ipsum hominem Deo vero tollit et immundis daemonibus subdit? Hoccine est sua cuique distribuere? An qui fundum aufert eius, a quo emptus est, et tradit ei, qui nihil habet in eo iuris, iniustus est; et qui se ipsum aufert dominanti Deo, a quo factus est, et malignis servit spiritibus, iustus est?" (AUGUSTINUS, 1955b, XIX, xxi, 2).

13 "Deus homini, animus imperat corpori, ratio libidini ceterisque vitiosis animi partibus". (AUGUSTINUS, 1955b, XIX, xxi, 2).
} 
mandar no corpo ou a razão humana nos vícios. Se em tal homem não existe justiça alguma, não há dúvida de que não existe em um conjunto de homens constituído de tais homens" ${ }^{\prime 14}$. Ou seja, há justiça quando o inferior submete-se ao superior e o superior impera sobre o inferior, assim como há ordem, de forma que, inversamente, a injustiça implica necessariamente na desordem.

\section{Religião, ontologia e politica (A cidade de Deus, XIX, xxii-xxiii)}

A querela entre Agostinho e Cícero acerca da definição de populus e o cumprimento ou não da virtude da justiça assenta-se em concepções distintas de "divindade". Não por acaso, imediatamente após recusar a definição ciceroniana de "povo" por meio da verificação da injustiça dos romanos devida ao paganismo, Agostinho passa a examinar precisamente a concepção de divindade do cristianismo e do paganismo.

O esforço de Agostinho é o de explicitar que, se existe um único Deus, o revelado pela doutrina cristã, os pagãos ainda assim consideravam a existência desse Deus quando afirmavam que, entre todos os deuses, Júpiter era o maior. Isso é atestado pelo panegírico que Porfírio realiza em Sobre a filosofia dos oráculos (Ek loghíon philosophias), Nesta obra, "o mais sábio dos filósofos, embora acérrimo inimigo dos cristãos" ${ }^{15}$, descreve um oráculo de Apolo segundo o qual o Deus dos judeus é o "gerador e o rei de todas as coisas"16. Além disso, diz Agostinho, "esse filósofo ainda diz coisas boas sobre Cristo"17, a despeito de julgá-lo homem e não Deus. De toda forma, Agostinho evidencia que o próprio paganismo considerou que Cristo foi piíssimo e que após a morte alcançou a imortalidade própria dos homens piedosos ${ }^{18}$. Porfírio, entretanto, relativiza tais encômios a Cristo, ainda por meio de Apolo, ao dizer que Cristo conduz seus seguidores ao erro, na medida em que ele não exorta os cristãos a renderem sacrifícios ao deuses e a conhecer Júpiter ${ }^{19}$. Agostinho, com isso, entende o caráter "sofístico" do panegírico de Porfírio e acusa-o de falsidade.

\footnotetext{
14 "Deo non serviens nullo modo potest iuste animus corpori aut humana ratio vitiis imperare. Et si in homine tali non est ulla iustitia, procul dubio nec in hominum coetu, qui ex hominibus talibus constat." (AUGUSTINUS, 1955b, XIX, xxi, 2).

15 "[Porphyrius] doctissimus philosophorum, quamvis Christianorum acerrimus inimicus". (AUGUSTINUS, 1955b XIX, xxii).

16 "In Deum vero, inquit, generatorem et in regem ante omnia". (AUGUSTINUS, 1955b, XIX, xxiii, 1).

17 "dicit etiam bona philosophus iste de Christo". (AUGUSTINUS, 1955b, XIXb, xxiii, 2).

18 "Piissimum igitur virum, inquit, eum dixit et eius animam, sicut et aliorum piorum, post obitum immortalitate dignatam". (AUGUSTINUS, 1955b, XIX, xxiii, 2).

19 "Illa vero anima aliis animabus fataliter dedit, quibus fata non adnuerunt deorum dona obtinere neque habere Iovis immortalis agnitionem, errore implicari." (AUGUSTINUS, 1955b, XIX, xxiii, 2).
} 
Quem é tão néscio que não entenda que tais oráculos foram inventados por esse homem ardiloso e grandioso inimigo dos cristãos ou foram proferidos com idêntico propósito pelos impuros demônios? O propósito seria fazer a gente acreditar, em face dos louvores tributados a Cristo, que têm razão, quando censuram os cristãos, fechando assim aos homens, quanto podem, o caminho da salvação eterna, a que não chegam, se não se fazem cristãos ${ }^{20}$.

Disso se pode depreender no mínimo duas coisas: (i) que os próprios pagãos atestam que o Deus dos judeus existe, e (ii) que os pagãos são injustos porque não se sujeitam a Cristo ao considerá-lo apenas homem. Assim, os pagãos não oferecem sacrifícios ao verdadeiro Deus, pois sequer admitem a encarnação. A consequência é serem necessariamente injustos, uma vez que apenas possui a virtude da justiça o homem que se sujeitar a Deus e no qual, por isso, a "alma impera retamente sobre o corpo, [...] e a razão impera retamente sobre a libido e os demais vícios" ${ }^{21}$.

Eis por que Agostinho, ao longo do capítulo contra Porfírio (De ciuitate dei, XIX, xxiii), cita seis vezes o versículo bíblico 22: "quem sacrificar aos deuses e não somente ao Senhor será aniquilado"23. O sacrifício, afinal de contas, é ação justa, é a primeira forma de manifestação da justiça, a partir da qual essa virtude ocupará todos os âmbitos de existência do homem e permitirá a emergência da paz na domus e na civitas. Mais precisamente, Agostinho define "sacrifício" da seguinte maneira: "o verdadeiro sacrifício é toda obra efetuada para nos unirmos a Deus em santa união, isto é, toda obra relacionada com o supremo bem, pelo qual podemos ser verdadeiramente felizes" ${ }^{24}$. Observemos não só a dimensão moral do "sacrifício", mas também a ontológica manifesta nessa modalidade de ação sagrada de relacionamento e união com o divino. Assim, "quem sacrificar aos deuses e não somente ao Senhor será aniquilado" porque os outros deuses não guardam plenitude de Ser, de forma que a erradicação ou aniquilação deve ser compreendida também como encaminhamento ao nada, como "nadificação", na medida em que houver ruptura da participação ontológica entre Criador e criatura.

\footnotetext{
20 "Quis ita stultus est, ut non intellegat aut ab homine callido eoque Christianis inimicissimo haec oracula fuisse conficta aut consilio simili ab impuris daemonibus ista fuisse responsa, ut scilicet, quoniam laudant Christum, propterea credantur veraciter vituperare Christianos atque ita, si possint, intercludant viam salutis aeternae, in qua fit quisque Christianus?" (AUGUSTINUS, 1955b, XIX, xxiii, 3).

21 "Serviens [autem] Deo animus recte imperat corpori, [inque ipso animo] ratio [Deo Domino subdita] recte imperat libidini vitiisque ceteris." (AUGUSTINUS, 1955b, XIX, xxi, 2).

${ }^{22}$ É notável a construção retórica e a exegese que Agostinho efetua nesse capítulo xxiii d'A cidade de Deus, XIX. Sua argumentação é inteiramente constituída em torno de seis citações de um único versículo bíblico.

23 "Sacrificans diis eradicabitur nisi Domino tantum'". (AUGUSTINUS, 1955b, XIX, xxiii); cf. Ex. 22, 19. A Bíblia de Jerusalém o traduz da seguinte forma: "quem sacrificar a outros deuses será entregue ao anátema".

24 "[...] verum sacrificium est omne opus, quo agitur, ut sancta societate inhaereamus Deo, relatum scilicet ad illum finem boni, quo veraciter beati esse possimus." (AUGUSTINUS, 1955b, X, vi).
} 
Um populus, portanto, não pode ser justo, e não será populus, se os cidadãos não oferecerem sacrifícios a Deus, se os cidadãos não ajustarem, não converterem, toda a sua existência em direção a Deus. Uma civitas, assim, será justa apenas se os cidadãos, interiormente, estiverem ordenados, ajustados com o supremo bem. A justiça, desse modo, apresenta-se em Agostinho como "dever sagrado" (sacrum officium ${ }^{25}$ ). A restrição do sacrifício ao Deus cristão justifica-se "não porque tenha necessidade de alguma coisa, mas porque nos convém ser coisa sua" 26 . Os falsos deuses, isto é, anjos falíveis, precisamente por não serem o próprio Criador e fundamento ontológico de todas as coisas, são incapazes de estabelecer qualquer mediação entre os homens e o divino. Por conseguinte, quem não sacrificar "somente ao Senhor será aniquilado" 27 .

Qual a consequência de toda essa análise sobre o divino, o sacrifício e a justiça para as definições ciceronianas de res publica e populus? Ora, se a justiça, para Cícero, é condição para um conjunto de homens ser considerado populus, e para uma res publica ser definida como coisa do povo, então apenas um povo e uma república cumprem aquele requisito. Com efeito, somente a cidade de Deus possui um povo capaz de exercer a virtude da justiça. A definição ciceroniana, então, é imprecisa. Carente de universalidade, refere-se a somente uma civitas particular. ${ }^{28}$

\section{Definição voluntarista de "justiça"}

Em XIX, xxiii, 5, Agostinho desenvolve a definição da virtude da justiça (dar a cada um o que lhe é devido) de duas maneiras. Ao explicar que somente o povo celeste, segundo a definição de Cícero, pode ser considerado populus, diz que isso se deve ao fato de em todos os cidadãos celestes o corpo estar submetido à alma, os vícios à razão, e, anteriormente, a alma estar submetida ao verdadeiro e único Deus ${ }^{29}$. Em seguida, Agostinho

\footnotetext{
${ }^{25}$ Embora Agostinho não faça menção alguma ao termo grego katórthoma (e conhecesse, contudo, o significado dele por meio do correspondente latino officium) podemos entender que o "ofício sagrado" (sacrificium) guarda aqui o sentido estoico de katórthoma (cf. CICERO. De officiis, 1963, I, iii, 8.), na medida em que é um dever que tem fim em si mesmo (deve-se ser justo pela justiça mesma). Cf. a caracterização agostiniana da caridade como officium ("officio caritatis") em De civitate Dei, XIX, xix.

26 "[...] non quo rei egeat alicuius, sed quia nobis expedit, ut res eius simus." (AUGUSTINUS, 1955b, XIX, xxiii, 5). (Tradução de Oscar Paes Leme).

27 “'Sacrificans diis eradicabitur nisi Domino tantum'”. (AUGUSTINUS, 1955b, XIX, xxiii); Ex. 22, 19.

28 "[...] ubi ergo non est ista iustitia, profecto non est coetus hominum iuris consensu et utilitatis communione sociatus. Quod si non est, utique populus non est, si vera est haec populi definitio. Ergo nec respublica est, quia res populi non est, ubi ipse populus non est." (AUGUSTINUS, 1955b, XIX, xxiii, 5).

29 "[...] in omnibus hominibus ad eamdem civitatem pertinentibus atque oboedientibus Deo animus etiam corpori atque ratio vitiis ordine legitimo fideliter imperet". (AUGUSTINUS, 1955b, XIX, xxiii, 5).
} 
confere à virtude da justiça outro sentido ao dizer que "um conjunto e povo de justos - como um só justo - vive da fé, que age pela caridade, graças à qual o homem ama a Deus, como Deus deve ser amado, e ao próximo como a si mesmo" ${ }^{30}$.

Assim, pode-se entender a justiça como a fé cuja ação é a caridade sob a forma dos dois preceitos cristãos. De fato, o verdadeiro Deus ao qual os homens devem submissão para serem justos precisa ser crido e amado a partir dessa condição, condição na qual a fé é necessária. Por que a fé é necessária? Porque na condição pecaminosa os homens ainda não veem a Deus face a face ${ }^{31}$. Além disso, a consideração da justiça por meio do amor apresenta a justiça segundo um voluntarismo, pois em Agostinho "vontade" e "amor" são sinônimos. Assim, a justiça, bem como todas as outras virtudes cardeais, são modalidades do amor: "a justiça é o amor que tão-somente serve a Deus e, por isso, impera sobre as demais coisas submetidas ao homem" ${ }^{\prime 32}$.

Notemos ainda que essa terceira formulação explicativa da justiça açambarca as duas formulações apresentadas em XIX, xxiii, 5. Com efeito, considera, a um só tempo, a justiça como a caridade ${ }^{33}$, submissão a Deus e domínio do homem sobre tudo que deve ser submetido a ele. Assim, por natureza o que havia era a ausência de conflito de cada homem consigo mesmo e, por consequência, ausência de conflito entre os homens, na família e na cidade. Isso quer dizer que a dominação ou o jugo de um homem sobre outro, a "libido de dominação"34, é antinatural. Eis por que a prescrição divina nas Escrituras era para o ser humano dominar tão somente os animais no paraíso e os primeiros justos terem sido pastores,

\footnotetext{
30 "[...] ut quemadmodum iustus unus, ita coetus populusque iustorum vivat ex fide, quae operatur per dilectionem, qua homo diligit Deum, sicut diligendus est Deus, et proximum sicut semetipsum". (AUGUSTINUS, 1955b, XIX, xxiii, 5).

31 "Agora vemos em espelho e de maneira confusa, mas, depois, veremos face a face. Agora o meu conhecimento é limitado, mas, depois, conhecerei como sou conhecido. Agora, portanto, permanecem fé, esperança, caridade, estas três coisas. A maior delas, porém, é a caridade" (1Cor. 13, 12-13); cf. AUGUSTINUS.1955b, XIX, iv, 5; XIX, xviii; XIX, xxvii.

32 "[...] iustitiam amorem Deo tantum servientem et ob hoc bene imperantem ceteris quae homini subiecta sunt". (AUGUSTINUS, De moribus ecclesiae catholicae, 2009, I, xv, p. 25).

${ }^{33}$ Apesar de essa definição de justiça fazer menção apenas ao amor a Deus, e não ao próximo, é preciso considerar que o segundo mandamento ("amar ao próximo como a si mesmo") está implícito no primeiro. Afinal, "amar a Deus" significa amar o Ser supremo do qual todos os seres participam ontologicamente. Nesse sentido, o próximo, como criatura de Deus, também deve ser amado. Ademais, por ser criatura como eu mesmo, amá-lo torna-se um dever ainda mais constringente. "Si placent animae, in Deo amentur, quia et ipsae mutabiles sunt et in illo fixae stabiliuntur: alioquin irent et perirent. In illo ergo amentur". (AUGUSTINUS, Confessiones, 1992, VI, xii, 18). Cf. ARENDT, H. O conceito de amor em Santo Agostinho, 1997, pp. 113-116. 34 "Na verdade, é preferível ser escravo de homem a sê-lo da libido, pois vemos quão tiranicamente exerce seu domínio sobre o coração dos mortais a própria libido de dominação". "Et utique felicius servitur homini, quam libidini, cum saevissimo dominatu vastet corda mortalium, ut alias omittam, libido ipsa dominandi." AUGUSTINUS.1955b, XIX, xv. Tradução de Oscar Paes Leme.
} 
não reis ${ }^{35}$. Dessa forma, a origem da tirania e da escravidão, seja a do homem consigo mesmo, seja a do homem sobre outro, guarda origem no pecado e na libido. É possível, entretanto, romper com a tirania da libido por meio da temperança, o que não significa extinguir o conflito e o vício, sempre presente na alma, domado ou indômito ${ }^{36}$. Isso quer dizer que a justiça relativa à condição fraturada não se realiza sem perturbações, o que retoma por que para Agostinho uma política com condições morais de realização não pode realizar-se na imanência.

\section{A "vontade" como fundamento de populus (A cidade de Deus, $X I X, x x i v)$}

O procedimento de Agostinho imediatamente antes de apresentar a sua definição de "povo" foi reduzir a justiça ao amor, porque o amor, não mais a justiça, torna-se o liame fundamental para um conjunto de homens constituir um povo. Eis a definição voluntarista apresentada por Agostinho: "Povo é a união de muitos seres racionais pela concorde comunidade das coisas que amam" ${ }^{37}$. Se, para constituir populus, a condição suficiente é uma multitudo guardar um amor partilhado, isso quer dizer que nem todo amor é justo. Mais precisamente, a condição para uma multitudo de seres racionais constituir populus é o amor, seja qual for, libidinoso ou ordenado, desde que partilhado por um objeto em comum. A ausência, porém, de critério moral para conceder estatuto político para um conjunto

\footnotetext{
35 “Trata-se de prescrição da ordem natural. Assim Deus criou o homem. 'Domine', diz, 'os peixes do mar, as aves do céu e todo réptil que se move sobre a terra' (Gn 1, 26). Quis que o homem racional, feito à sua imagem, dominasse unicamente os irracionais. Eis o motivo de os primeiros justos haverem sido pastores e não reis." "Hoc naturalis ordo praescribit, ita Deus hominem condidit. Nam: Dominetur, inquit, piscium maris et volatilium caeli et omnium repentium, quae repunt super terram $(\mathrm{Gn} 1,26)$. Rationalem factum ad imaginem suam noluit nisi irrationabilibus dominari; non hominem homini, sed hominem pecori. Inde primi iusti pastores pecorum magis quam reges hominum constituti sunt (Gn 4, 2; 46, 32-34; 47, 3; Ex 3, 1)." (AUGUSTINUS.1955b, XIX, xv). Cf. SENELLART, As artes de governar, 2006, p. 72.

36 "Que diremos da virtude chamada prudência? Sua vigilância toda não se encaminha a discernir os bens dos males, para sem erro buscar os primeiros e fugir dos segundos? Ela mesma é prova de estarmos no mal e de o mal estar em nós. Ensina-nos que é mal consentir na libido pecaminosa e bem não consentir nela. $O$ mal que a prudência nos ensina a não consentir e a temperança nos faz combater nem a prudência, nem a temperança o descartam desta vida." "Quid illa virtus, quae prudentia dicitur, nonne tota vigilantia sua bona discernit a malis, ut in illis appetendis istisque vitandis nullus error obrepat, ac per hoc et ipsa nos in malis vel mala in nobis esse testatur? Ipsa enim docet malum esse ad peccandum consentire bonumque esse ad peccandum non consentire libidini. Illud tamen malum, cui nos non consentire docet prudentia, facit temperantia, nec prudentia nec temperantia tollit huic vitae.". (AUGUSTINUS, 1955b, XIX, iv, 4). Tradução de Oscar Paes Leme.

37 "Populus est coetus multitudinis rationalis rerum quas diligit concordi communione sociatus". (AUGUSTINUS, 1955b, XIX, xxiv). "Augustine replaces Cicero's definition of a community [...] with a definition of his own which excludes all mention of 'right'". (O'DONOVAN, 1995, p. 139).
} 
de homens não significa divórcio necessário entre política e moral, nem pretende conceder positividade para uma autonomia da política. Afinal, sabemos desde o prólogo d'A cidade de Deus que a distinção de excelência da cidade celeste peregrina reside em sua progressiva conquista de moralidade e identidade. Ainda assim, por que conferir estatuto político para um conjunto de homens moralmente desorientados? Por que não admitir que só a cidade celeste possui povo e a cidade terrena não é cidade e seus integrantes não formam "povo"? Ora, precisamente para demarcar a negatividade da autonomia da política, que nada mais é do que alargamento do desejo de autonomia do homem em relação a Deus, isto é, a "libido de dominação", fundo histórico comum de ambas as cidades, mas de que somente uma procura destacar-se.

Não à toa, toda a análise histórica e política, toda a análise pormenorizada da História de Roma, realizada nos cinco primeiros livros d'A cidade de Deus, está a serviço da moral. Tanto é que imediatamente após a apresentação de sua definição de "povo", Agostinho afirma com todas as letras que não se trata de estimar todos os povos apenas por serem "povos" e terem edificado "repúblicas", pois "para ver o que é cada povo, é preciso examinar as coisas amadas", e um povo será "tanto melhor quanto melhores as coisas que o unir, e tanto pior quanto piores forem" ${ }^{\prime 38}$. Assim, a política com fim em si mesma é pensada e criticada por Agostinho a partir da noção de "libido de dominação", modalidade de "vontade" ou "amor" constitutivo e contraproducente da cidade terrena. Aliás, A cidade de Deus pode ser lida como uma crítica a essa concepção de política divorciada da moral, conforme Agostinho mesmo anuncia no prólogo da obra.

Por isso, também a respeito da cidade terrena -, que com o desejo de dominar, e não obstante povos sejam seus escravos, é dominada pela própria libido de dominação -, não deixarei passar em silêncio tudo aquilo que o plano desta obra exigir e a minha capacidade permitir dizer. ${ }^{39}$

Como todo desejo, a libido deseja o gozo (frui), porém em se tratando de uma figura depravada do desejo, a libido deseja o gozo ilegítimo. No âmbito da política, a dominação e escravização do outro é o desfrute desejado. Por isso, a forma de governo com a qual comumente a cidade terrena se manifesta é a tirania, como institucionalização ou exteriorização de tirania anterior e interior, que é a libido presente em cada um de seus cidadãos ${ }^{40}$. A libido, porém, também está presente nos cidadãos celestes peregrinos, embora neles não seja tirânica, mas combatida e reprimida pela virtude.

\footnotetext{
38 "[...] profecto, ut videatur qualis quisque populus sit, illa sunt intuenda, quae diligit. [...] tanto utique melior, quanto in melioribus, tantoque deterior, quanto est in deterioribus concors.". (AUGUSTINUS, 1955b, XIX, xxiv).

39 "Unde etiam de terrena civitate, quae cum dominari adpetit, etsi populi serviant, ipsa ei dominandi libido dominatur, non est praetereundum silentio quidquid dicere suscepti huius operis ratio postulat si facultas datur.". (AUGUSTINUS, 1955a, praefatio). Nossa tradução.

40 "Quis enim facile dixerit, quid vocetur libido dominandi, quam tamen plurimum valere in tyrannorum animis etiam civilia bella testantur?".(AUGUSTINUS, 1955b, XIV, xv, 2).
} 
Política e libido, assim, são indissociáveis na reflexão política agostiniana. Afinal, a libido é o fundamento da política e da história da cidade terrena, bem como é dela que a cidade celeste busca libertar-se em sua peregrinação.

Em suma, a desnaturalização e a ambivalência da política $n^{\prime} A$ cidade de Deus é exigência de reflexão sobre a história e a condição humana que ao deparar com a contradição, o conflito, a violência, a tortura, os estupros, a guerra e a morte encontra o que contemporaneamente chamaríamos de facticidade. Agostinho, dessa maneira, não empreende análise sobre o histórico e a partir da presença ou ausência nele de conceitos de razão comprometidos com a identidade, como a natureza, a unidade e o Ser, que estariam dados a priori. Ao contrário, o ponto de partida é o próprio histórico, verificado irredutível e, quase sempre, averso àqueles conceitos. Se não houvesse a irredutibilidade, ele deixaria de ser histórico e seria preciso negar a contradição e o conflito da condição humana. É por isso, aliás, que Agostinho precisa recusar qualquer concepção de política fundamentada na natureza ou na razão, como em Cícero.

Portanto, a realidade onde a identidade e a paz imperem só pode subsistir efetivamente na transcendência, não na imanência, o que antes de ser limitação filosófica, é expediente e condição para análise da história e da política que conceda a ambas fundamento e princípio que possam ser imanentes. Reside aí possibilidade de emergência do conceito de vontade no pensamento agostiniano. Afinal, a vontade ou o amor por definição é dinâmica em direção a um fim em que se pretende satisfazer a falta. Por conseguinte, a ambivalência da vontade não consiste somente na positividade ou negatividade, no virtuosismo ou na viciosidade, adquirida conforme o lugar para onde é direcionada, mas também, precisamente por isso, na possibilidade de desempenhar função de princípio tanto imanente, como transcendente, da política.

\section{Referências bibliográficas:}

Fontes primárias:

AUGUSTINUS. Confessionum libri tredecim. Patrologia Latina Tomus 32. Turnhout: Brepols, 1992.

De civitate dei (Libri I-X). Corpus Christianorum Series Latina XLVII. Turnhout: Brepols, 1955a.

. De civitate dei (Libri XI-XXII). Corpus Christianorum Series Latina XLVIII. Turnhout: Brepols, 1955b.

. A cidade de Deus. (contra os pagãos). 2 volumes. Trad. Oscar Paes Leme. Petrópolis: Vozes, 2002.

De moribus ecclesiae catholicae et de moribus manichaeorum. Corpus Scriptorum Latinorum. Sancti Aureli Augustini Opera sect..VI, pars VII. Vindobonae (Viena): Austrian Academy of Sciences Press, 2009. 
CICERO. De re publica. Leipzig: Bibliotheca Scriptorum Graecorum et Romanorum Teubneriana, 1964.

. De Officiis. Leipzig: Bibliotheca scriptorum Graecorum et Romanorum

Teubneriana, 1963.

\section{Fontes secundárias:}

ADAMS, J. D. "Augustine's Definitions of Populus and the Value of Civil Society". In:

DONNELLY, D. F. The City of God - A Collection of Critical Essays. New York: Peter Lang, 1995, p. 171-182.

ARENDT, H. O conceito de amor em Santo Agostinho. Trad. Dinis, A. P. Lisboa: Instituto Piaget, 1997.

CHAX-RUY, J. Saint Augustin - Temps et Histoire. Paris: Études Augustiniennes, 1956.

GILSON, É. Evolução da Cidade de Deus. São Paulo: Herder, 1965.

GILSON, É. Introdução ao estudo de santo Agostinho. Trad. Ayoub, C. N. A. São Paulo: Discurso Editorial; Paulus, 2006.

GUY, J-C. Unité et structure logique de la "Cité de Dieu"de saint Augustin. Paris: Études Augustiniennes, 1961.

MARKUS, R. A. Saeculum: History and Society in the Theology of St Augustine. Cambridge: Cambridge University Press, 1970.

MARROU, H-I. L'ambivalence du temps de l'histoire chez saint Augustin. Montréal-Paris: Vrin, 1950.

193-212.

. "La théologie de l'histoire", Augustinus Magister, III, Paris, 1954, p.

O'DONOVAN, O. "Augustine's City of God XIX and Western Political Thought". In: DONNELLY, D. F. The City of God - A Collection of Critical Essays. New York: Peter Lang, 1995, pp. 135-149.

POWELL, J. G. F. “Cicero's Definition of Res Publica" In Cicero the philosopher Twelve papers. Oxford: Clarendon Press, 1995.

SENELLART, M. As artes de governar: do regimen medieval ao conceito de governo, trad. Paulo Neves. São Paulo: Editora 34, 2006.

SILVA FILHO, L. M. "A conjunção et na definição ciceroniana de populus". Cadernos de Filosofia Alemã, 21, jan-jun 2013, pp. 85-96.

. A definição de populus n'A cidade de Deus de Agostinho: uma controvérsia com Da república de Cícero. Dissertação de Mestrado em Filosofia, São Paulo, USP, 2008.

. Desnaturalização da política n'A cidade de Deus, de Agostinho.

Tese de Doutorado em Filosofia, São Paulo, USP, 2012.

Endereço do Autor:

R. José Buischi, 67, Jd. Independência,

14076-470 Ribeirão Preto - SP

lmarcosfilho@gmail.com 